\title{
Eco Friendly Sorbent for the Removal of Iron and Lead from Industrial Waste Water
}

\author{
Renjusha $\mathrm{S}^{1}$, Shyama Nair ${ }^{2 *}$ \\ ${ }_{1 \& 2}$ Department of Chemistry, N.S.S. College, Pandalam, Pathanamthitta, India
}

\begin{abstract}
Industrial effluents loaded with heavy metals are a cause of hazards to human and other forms of life. Conventional methods such as chemical precipitation, evaporation, electroplating, ion exchange, reverse osmosis etc., used for removal of heavy metals from waste water however, are often cost prohibitive having inadequate efficiencies at low metal ion concentrations. Biosorption can be considered as an alternative technology which has been proved as more efficient and economical for removal of heavy metals from the industrial waste water. In the present study, the adsorption capacity of epicarp of Atrocarpus heterophyllus for the removal of heavy metals, lead and iron were determined by batch adsorption studies. Adsorption of heavy metals were studied till equilibrium was reached. Studies were carried by using different doses of adorbent, varying the conditions of adsorption and contact time. The results obtained shows that, the adsorption of the metal ions is contact time and adsorbent dosage dependent. Adsorption studies obeys both Langmuir isotherm model and Freundlich models. The goal for this work is to develop inexpensive, highly available, effective adsorbents from epicarp of jackfruit as alternative to existing commercial adsorbents.
\end{abstract}

Keywords : Heavy Metal, Low Cost Adsorbent, Wastewater, Adsorption Isotherm.

\section{INTRODUCTION}

Water used in industry creates wastewater that has a potential hazard for our environment because of introducing various contaminants such as heavy metals into soil and water resources. Heavy metal ions are nowadays among the most important pollutants in surface and ground water [1]. The safe and effective disposal of industrial wastewater is thus a challenging task for industrialists and environmentalists. Nowadays, with the exponential increase in population, measures for controlling heavy metal emissions into the environment are essential [2]. Lead causes many serious disorders like, anemia, kidney disease, nervous disorders, and even death, it heads the toxic element list of 2008 [3]. New approaches based on the use of natural inexpensive adsorbents for treatment have been reported [4]. In general, an adsorbent can be termed as a low cost adsorbent if it requires little processing, is abundant in nature, or is a by-product or waste material from another industry [5].

To avoid health hazards it is essential to remove toxic heavy metals from waste water before its disposal. Adsorption process is widely used in the removal of heavy metals. Understanding the sorption of metal ions from aqueous solution is important in water pollution control. Therefore there is an urgent need that all possible sources of agro-based inexpensive adsorbents should be explored and their feasibility for the removal of heavy metals should be studied in 
detail [6]. The objective of this study is to contribute in the search for less expensive adsorbents and their utilization possibilities for various agricultural waste by-products which are in many cases also pollution sources. Based on this fact the present study was proposed to evaluating the applicability and the efficiency of the newly chosen agricultural wastes as natural adsorbent such as epicarp of Atrocarpus heterophyllus . The use of these locally available agricultural for removal of lead and iron from aqueous solutions at different experimental conditions is an alternative waste management or environmental conservation. The adsorption capacity of epicarp of Atrocarpus heterophyllus for the removal of heavy metals, lead and iron were determined by batch adsorption studies. Adsorption of heavy metals were studied till equilibrium was reached. Studies were carried by using different doses of adorbent, varying the conditions of adsorption and contact time.

\section{MATERIALS AND METHODS}

\subsection{Materials}

All the chemicals used were of analytical grade reagent. A stock solution of lead nitrate $(0.6256 \mathrm{~g} /$ $500 \mathrm{ml})$ and $\mathrm{FeSO}_{4} .7 \mathrm{H}_{2} \mathrm{O}(0.20088 \mathrm{~g}$ of $\mathrm{Fe}$ in $500 \mathrm{ml})$ were used as adsorbate and solutions of various concentrations $(15,25,50,75 \& 100 \mathrm{mg} / \mathrm{L})$ were obtained by diluting the stock solution with distilled water. The epicarp of jackfruit was collected after the removal of pericarp. Washed repeatedly with distilled water and dried in sunlight. The dried epicarp was powdered and sieved to obtain same mesh size of $425-600 \mathrm{~nm}$.

\section{RESULTS AND DISCUSSION}

The adsorption capacity of epicarp of jackfruit for the removal of $\mathrm{Pb}^{2+}$ and $\mathrm{Fe}^{2+}$ were determined by batch adsorption studies. Adsorption studies were carried out for three days at the intervals of $24 \mathrm{hrs}$ and the $\mathrm{pH}$ of the solution was maintained at 9. Adsorbent is weighed and about $1 \mathrm{~g}, 2 \mathrm{~g}$ and $\mathrm{gg}$ of it is taken in 150 $\mathrm{ml}$ beakers. Two batches were prepared. To the first set of three beakers containing different doses of adsorbent $100 \mathrm{ml}$ of $\mathrm{FeSO}_{4} .7 \mathrm{H}_{2} \mathrm{O}$ was added. To the second set $100 \mathrm{ml} \mathrm{PbNO}_{3}$ was added. Two sets of beakers with different adsorbent doses was shaken in rotary shaker and kept overnight. $10 \mathrm{ml}$ of supernatant liquid from each beaker was withdrawn, filtered and collected at the intervals of $24 \mathrm{hrs}, 48 \mathrm{hrs}$ and $72 \mathrm{hrs}$. The residual lead and iron concentration was measured by ICP-AES system (model no: Thermo Electron IRIS Intrepid II XSP DUD). The parameters studied were the optimum dosage, time taken for maximum adsorption and isotherm studies. Results are shown in the tables below.

Table-1

\begin{tabular}{|c|c|c|c|}
\hline \multirow[b]{2}{*}{$\begin{array}{l}\text { Time of } \\
\text { adsorption }\end{array}$} & \multicolumn{3}{|c|}{$\%$ of $\mathrm{Fe}^{2+}$ adsorbed } \\
\hline & $\begin{array}{l}1 \mathrm{~g} \text { of } \\
\text { adsorbent }\end{array}$ & $\begin{array}{l}2 \quad \mathrm{~g} \text { of } \\
\text { adsorbent }\end{array}$ & $\begin{array}{l}3 \mathrm{~g} \text { of } \\
\text { adsorbent }\end{array}$ \\
\hline $24 \mathrm{hrs}$ & $73.29 \%$ & $80.00 \%$ & $81.92 \%$ \\
\hline $48 \mathrm{hrs}$ & $84.84 \%$ & $90.00 \%$ & $90.00 \%$ \\
\hline $72 \mathrm{hrs}$ & $90.07 \%$ & $94.00 \%$ & $98.00 \%$ \\
\hline
\end{tabular}

Table-2

\begin{tabular}{|c|c|c|c|}
\hline \multirow[b]{2}{*}{$\begin{array}{l}\text { Time of } \\
\text { adsorption }\end{array}$} & \multicolumn{3}{|c|}{$\%$ of $\mathrm{Pb}^{2+}$ adsorbed } \\
\hline & $\begin{array}{l}1 \mathrm{~g} \text { of } \\
\text { adsorbent }\end{array}$ & $\begin{array}{l}2 \mathrm{~g} \text { of } \\
\text { adsorbent }\end{array}$ & $\begin{array}{l}3 \mathrm{~g} \text { of } \\
\text { adsorbent }\end{array}$ \\
\hline $24 \mathrm{hrs}$ & $91.57 \%$ & $96.00 \%$ & $97.00 \%$ \\
\hline $48 \mathrm{hrs}$ & $97.02 \%$ & $98.00 \%$ & $98.00 \%$ \\
\hline $72 \mathrm{hrs}$ & $99.23 \%$ & $99.55 \%$ & $100.00 \%$ \\
\hline
\end{tabular}

Basically, the efficiency of adsorption strongly depends upon the time of adsorption. So the effect of contact time in the adsorption of iron and lead was studied. The results shows the maximum adsorption was found at $72 \mathrm{hrs}$ and the equilibrium adsorption was attained after about 72 hrs. 
The effect of adsorbent dosage was also investigated using $1 \mathrm{~g}, 2 \mathrm{~g}$ and $3 \mathrm{~g}$ of adsorbent by fixing the contact time. The result was that there is gradual increase in removal efficiency of ions with corresponding increase in adsorbent concentration which may be attributed to the increasing presence of adsorption sites. However, as the binding sites get saturated, adsorption is independent of concentration of the adsorbent.

\section{Adsorption Isotherms}

Langmuir and Fruendlich adsorption models were applied to analyse adsorption data and both are found to be applicable for these process.

Langmuir adsorption is expressed as $\mathrm{Ce} / \mathrm{X}=\mathrm{Ce} / \mathrm{Xmax}$ $+1 / \mathrm{Xmax} b$

Where Ce is the equilibrium or final concentration in ppm, $\mathrm{X}$ is the amount of Fe adsorbed per unit weight of adsorbent at equilibrium concentration, $\mathrm{X}$ is the maximum adsorption at monolayer coverage and $\mathrm{b}$ is the adsorption equilibrium constant.

Table -3. Isotherm parameters for Iron

\begin{tabular}{|l|l|l|l|l|}
\hline $\mathrm{Ce}$ & $\mathrm{x} / \mathrm{m}$ & $\mathrm{Ce} / \mathrm{x} / \mathrm{m}$ & $\log \mathrm{Ce}$ & $\begin{array}{l}\log \\
\mathrm{x} / \mathrm{m}\end{array}$ \\
\hline 0.2008 & $1.4893 \times 10^{-3}$ & 134.82 & 0.6972 & 2.8270 \\
\hline 0.4216 & $3.0728 \times 10^{-3}$ & 137.20 & 0.3750 & 2.5124 \\
\hline 0.6244 & $4.4680 \times 10^{-3}$ & 139.30 & 0.2059 & 2.2222 \\
\hline
\end{tabular}

Table -4. Isotherm parameters for Lead

\begin{tabular}{|l|l|l|l|l|}
\hline $\mathrm{Ce}$ & $\mathrm{x} / \mathrm{m}$ & $\mathrm{Ce} / \mathrm{x} / \mathrm{m}$ & $\log \mathrm{Ce}$ & $\log \mathrm{x} / \mathrm{m}$ \\
\hline 0.6600 & $\begin{array}{l}3.8823 \\
\mathrm{x} 10^{-3}\end{array}$ & 170.00 & 0.1080 & 2.1410 \\
\hline 1.5100 & $\begin{array}{l}3.4084 \\
\mathrm{x} 10^{-3}\end{array}$ & 414.30 & 0.1492 & 2.3110 \\
\hline 1.5667 & $\begin{array}{l}3.4285 \\
\mathrm{x} 10^{-3}\end{array}$ & 627.00 & 0.2552 & 2.4666 \\
\hline
\end{tabular}

The plot of $\mathrm{Ce} / \mathrm{x} / \mathrm{m}$ against Ce should be a straight line in the case of both iron and lead. Thus this study of adsorption obeys the Langmuir isotherm model and unimolecular adsorption is very clearly observed. Epicarp of jackfruit is a very good adsorbent, adsorption can be at unimolecular level or at bimolecular level as it obeys both Langmuir and Freundlich adsorption isotherm.

\section{CONCLUSION}

The effectiveness and potential of the adsorption process by using a low cost adsorbent, epicarp of jackfruit was studied. Studies were carried by using different doses of adorbent, varying the conditions of adsorption and contact time ${ }^{5}$. The residual amount of heavy metals was withdrawn periodically and analysed. The concentrations of heavy metals were measured by ICP - AES system. Optimum dosage, contact time required for the equilibrium adsorption and isotherm studies were assessed. Effect of adsorbent dose on the rate of adsorption of metal ions was assessed by fixing the contact time and other parameters. High removal efficiency was found when maximum amount of dose of $3 \mathrm{~g}$ of adsorbent was used. Above $90 \%$ of adsorption could be seen for lead and iron when a maximum amount of $3 \mathrm{~g}$ of adsorbent was used. A very effective removal of ions was found when the adsorbent dose was found to be $3 \mathrm{~g}$. A contact time of 72 hours was found to remove a maximum of $98 \%$ of the metal ions. Changing the temperature of the studies, $\mathrm{pH}$ of the solutions and continuous stirring can bring variations in the adsorption to a very little extent only. Adsorption studies obeys both Langmuir isotherm model and Freundlich models. Adsorption can be at unimolecular or at bimolecular levels. The adsorbent used is easily available, low cost and even the disposal of it to the environment do not cause any harm. The results also proves a wide opportunity of using the eco friendly adsorbent in the field of heavy metal adsorption with a maximum removal efficiency. 


\section{ACKNOWLEDGEMENTS}

Authors are grateful to N.S.S. College, Pandalam, Kerala and SAIF, CUSAT, India for analysis.

\section{REFERENCES}

[1]. L. Brinza , C.A. Nygård., M.J.Dring, M. Gavrilescu. \& L.G. Benning (2009). Cadmium tolerance and adsorption by the marine brown alga Fucus vesiculosus from the Irish Sea and the Bothnian Sea, Bioresource Technology, 100, 1727-1733.

[2]. S. Davydova (2005). Heavy metals as toxicants in big cities, Microchemical Journal, 79, 133136.

[3]. C.Karthika, N. Vinnilamani, S. Pattabhi \& M.Sekar (2010). Utilization of Sago Waste as an Adsorbent for the Removal of $\mathrm{Pb}$ (II) from Aqueous Solution: Kinetics and Isotherm Studie International Journal of Engineering Science and Technology, Vol. 2 (6), 18671879.Ecosystem, 2nd Iran International Zeolite Conference, April 29-30. Tehran, Iran.

[4]. J.C.P.Vaghetti, E.C.Lima, B. Royer, B.M. da Cunha, N.F.Cardoso, J. L Brasil., \& S.L.P. Dias (2009). Pecan nutshell as biosorbent to remove $\mathrm{Cu}(\mathrm{II}), \mathrm{Mn}(\mathrm{II})$ and $\mathrm{Pb}(\mathrm{II})$ from aqueous solutions, Journal of Hazardous Materials, 162, 270-280.

[5]. M. Malakootian, J. Nouri, \& H. Hossaini (2009). Removal of heavy metals from paint industry's wastewater using Leca as an available adsorbent. Int. J. Environ. Sci. Tech., 6 (2), 183190.

[6]. J. Acharya, J.N. Sahub, C.R. Mohanty, B.C. Meikap (2009) Removal of lead(II) from wastewater by activated carbon developed from Tamarind wood by zinc chloride activation. Chem Eng J 149:249-262.

[7]. N. Maximous, F. George., \& K.Wan (2010). Removal of Heavy Metals from Wastewater by
Adsorption and Membrane Processes: a Comparative Study, World Academy of Science, Engineering and Technology, 64.

Cite this article as :

Renjusha S, Shyama Nair, " Eco Friendly Sorbent for the Removal of Iron and Lead from Industrial Waste Water, International Journal of Scientific Research in Science and Technology(IJSRST), Print ISSN : 23956011, Online ISSN : 2395-602X, Volume 6, Issue 1, pp.125-128, January-February-2019. Available at doi : https://doi.org/10.32628/IJSRST196117 Journal URL : http://ijsrst.com/IJSRST196117 